\title{
Introduction to the Special Issue: Things We Do and Don't Understand About the Household and the Environment
}

\author{
Alistair Munro
}

Received: 16 March 2009 / Accepted: 26 March 2009 / Published online: 19 April 2009

(C) Springer Science+Business Media B.V. 2009

\begin{abstract}
Environmental economics has been slow to incorporate the full and complex nature of the household into its analytical structures and to reflect empirical evidence on household decision-making. This paper provides an overview of some of the main unanswered questions.
\end{abstract}

Keywords Household · Environmental economics · Unitary model · Children · Stated preference

JEL Classification C920 - D130 - D80

\section{Introduction}

It is well-known that the words "economics" and "ecology" share a common origin in the Greek word for household, "oikos". Despite the intimate link between the two sources of our field, environmental economics has been slow to incorporate the full nature of the household into its analytical structures. The aim of this special issue is therefore to bring together research in the field and to stimulate further enquiry. All of the papers are empirical, but they vary in their methods and their motives. The papers share the perspective that an accurate understanding of household behaviour is vital for environmental economics. In this introduction, I provide an overview by way of identifying some things that are already know about the relationship between the environment and the households and some areas where I suspect we need much more research.

\footnotetext{
A. Munro ( $\varangle)$

National Graduate Institute for Policy Studies, 7-22-1 Roppongi,

Minato-ku, Tokyo 106-8677, Japan

e-mail: alistair-munro@grips.ac.jp
} 


\section{Two Things We Already Know About the Household and the Environment}

Although research on the environment and the household has rarely been systematic, there are a couple of broad facts that are well established.

\subsection{Environmental Risks and Benefits are Linked to Age and Gender}

This is perhaps an obvious point to make, but it bears some repeating and illustration with a few examples. According to Bruce et al. (2000), up to 2 million excess deaths each year are attributable to the effects of poor combustion efficiency of rudimentary wood and coal burning stoves. Women (and young children) tend to be more at risk than men from the effects of the indoor pollution created during cooking on inefficient stoves using dirty fuels. Comparing families living in quiet streets and high traffic density routes in the Netherlands, Oosterlee et al. (1996) find that female children living near busy roads suffer significantly more respiratory problems than male children. Partly because of their smaller size, children are more vulnerable than healthy adults to the dangers of contaminated food and water, particularly in developing countries (Barua and Greenough 1992). Children's behaviour and their younger age means that skin cancer risks are disproportionately acquired during childhood (Stern et al. 1986). In this issue, Hammitt and Stackelberg (2009), present a valuation study from the USA, which takes as its starting point the differential risks to the foetus from polychlorinated biphenyl (PCB) compounds via freshwater fish intake. Because of differential occupational patterns in richer nations, men meanwhile are more likely to be exposed to cancer-causing particulates (Vineis et al. 2004).

Access to environmental resources can also differ between the sexes, as Agarwal (2001) documents in her extensive work on the collective management of forests in India and Nepal. She shows how women are routinely excluded from decision-making processes and as a result, production from forests is tilted towards men's desires. Zwarteveen and MeinzenDick (2001) paint a similar picture for access to irrigation water in South Asia, but also argue that creating property rights over water can reduce female control in regions where it is difficult legally for women to own land.

The genders also differ (on average) in the perceived risks of specific environmental problems. In particular it is widely documented that in North America, white men perceive environmental risks to be lower than other social groups (Flynn et al. 1994, provides a summary of the evidence). Stern et al. (1993) argues that women are more informed and aware of environmental risks. In a specific example using a mail-based survey of Hamilton residents, Dupont (2004) finds that women, especially those with children, are more alert to the risks of swimming in Lake Ontario, compared to men.

Although we know that risks differ, it is probably not wise to overstate the extent of current understanding. Wagner and Blais (2007) emphasise (see also EPA 2003 and Landrigan and Garg 2002) the particular gap in knowledge about the actual differences in environmental risks between children and adults. It is also worth reminding ourselves that gender and age are of course not the only forces driving differential costs and benefits. In this issue for example, Huhtala and Pouta (2009) consider the benefits from recreational areas in Finland, using travel cost data. Men and older people profit more, but they argue that income is the biggest driver of disparities in the benefits. 


\subsection{The Unitary Model is Generally Wrong}

In the unitary model, the household acts as if it is a single individual maximizing a single utility function in the face of one budget constraint. It is a simplifying modelling assumption that is widely used in most branches of economics, but it is wrong. The fact that the unitary model is inaccurate is well-known and has been known for many years now (Alderman et al. 1995). If the model was correct, then the source of household income would not affect patterns of expenditure- there would be income pooling. But instead, the source of income does affect expenditure, as was most clearly shown by Lundberg et al. (1997), using the natural experiment provided by a reform of the UK tax system that turned child tax allowances (typically paid to the male adult in the household) into child benefit (typically received by the female). These results have been widely confirmed for other countries (e.g Attanasio and Lechene 2002 for Mexico or Anderson and Baland 2002 for Kenya) and using experimental data (Bateman and Munro 2005). If the unitary model were correct, then estimated household demand functions would also produce a Slutsky substitution, $S$, that was symmetric. But as Browning and Chiappori (1998) show using Canadian data, estimates of $S_{-}-S^{\prime}$ (where $S^{\prime}$ is the transpose of $S$ ) are of rank 2 , which is compatible with a collective model of a two person household but not with the unitary model.

The fact that the unitary model is generally wrong has implications for both our understanding of environmental valuation and for the behavioural effects of policies. Now, most economic models are wrong in the detail. The key issue is whether they are still sufficiently useful for the topic at hand. For instance, Manuel Frondel and Colin Vance in this issue use a unitary model perspective to provide evidence on an important policy issue: the sensitivity of household behaviour to changes in the price of fuel prices. Using evidence from German households, they estimate the rebound effect and show that fuel taxation may have a substantial impact in lowering fuel consumption and, hence, greenhouse gas emissions for many household types. Similarly, Dickie and Gerking (2009) use data on sun-cream purchases in the USA. They show that revealed preferences by parents towards children's skin cancer risks provide a good fit to a relationship consistent with the unitary model. Specifically, a parent's marginal rate of substitution between equal percentage reductions in her child's and her own risk is equal to 1 . The unitary model is also, possibly still the most useful workhorse for analysing the optimal long-run use of a non-renewable resource for instance. But, in other areas of environmental economics, a better understanding of how household allocate resources is a vital element in the process of understanding the impact of policies on society at large.

\section{Four Things We Do Not Yet Understand About the Household and the Environment}

This list is not meant to be exhaustive, but it picks out some specific areas where further research would be valuable.

\subsection{How Best to Model Household Decision-Making}

There is something of a conundrum in the fact that alternative models of household behaviour may enrich policy analysis, but at the moment we do not understand how analysis is altered, because alternatives to the unitary model are so rarely employed in environmental economics. If theory is developed and estimated, then we can begin to make some judgement about when 
and where it is appropriate to drop the unitary model and engage with a household model that is more realistic, but probably messier to handle.

Consider the following simple example. A two person household consumes commodities $x$ and $y$. The good $x$ produces carbon emissions. Only person 1 likes $x$. The good $y$ produces no emissions. It is only liked by person 2. Person $i$ brings income $m_{i}$ to the household and gains the utility equivalent of $\Delta i$ of their preferred good (i.e. $x$ or $y$ ) from being in the relationship. This means that there are costs for each partner from the dissolution of the relationship. Consumption is determined by maximizing the Nash product, $\left[x-\left(m_{1}-\Delta_{1}\right)\right]\left[y-\left(m_{2}-\Delta_{2}\right)\right]$ subject to the constraint that $\mathrm{x}+\mathrm{y}=\mathrm{m}_{1}+\mathrm{m}_{2}$. In this situation we get, $\mathrm{x}=\left(\mathrm{m}_{1}-0.5\left(\Delta_{1}-\Delta_{2}\right)\right)$. In other words, the person who feels the pain of separation less, gains consumption from the bargain relative to the other partner. Now suppose we introduce a carbon tax of $t$ levied on expenditure on $\mathrm{x}$ and this generates revenue which is given to the household in lump-sum form T. We can consider two polar cases. In the first case, $\mathrm{T}$ is given to the consumer of $\mathrm{x}$, who will also receive it if the relationship is dissolved. Perhaps person 1 is the sole wage earner, and the revenue is used to lower taxes on wage income. The problem is now to maximize,

$$
\left[x-\frac{\left(T+m_{1}-\Delta_{1}\right)}{1+t}\right]\left[y-m_{2}-\Delta_{2}\right]
$$

subject to $x(1+t)+y=T+m_{1}+m_{2}$. In this situation, we get $x=\left(T+m_{1}-0.5\left(\Delta_{1}-\right.\right.$ $\left.\left.\Delta_{2}\right) /(1+t)\right)$. If the tax budget is required to balance and there is a representative household, then in fact we get, $x=\left(m_{1}-0.5\left(\Delta_{1}-\Delta_{2}\right)\right)$. In other words the carbon tax has no effect on consumption of the externality producing good. At the other extreme, $T$ could be given to the other partner. Perhaps for instance, it is given to non-wage earners to help support family life. The new equilibrium value of $x$ is $\left(m_{1}-0.5\left(\Delta_{1}-\Delta_{2}\right) /(1+t)\right)$. In this case the payment of $T$ does not affect $x$. Instead a $1 \%$ rise in the value of $(1+t)$ leads to a $1 \%$ fall in consumption of $x$. The carbon tax has an effect.

The key point here is that in a unitary model, it would not matter who received the payment of T. Having a richer model demonstrates that who receives the tax cut matters for the effectiveness of the policy. Despite the specific nature of the example, this is a general point and one that has been explored in the recent public economics literature (e.g. Apps and Rees 2009). Now many environmental policies such as green taxes, efficiency standards, recycling rules etc. are directed in part at the consumer. If we have an inadequate model of household behaviour, then we are potentially mis-predicting responses to policy.

A second lesson implicit in the example is the importance of the fallback in determining the household allocation. If bargaining power is unaffected by policy variables such as taxes, then the collective model of the household is essentially reduced to the unitary (though possibly with an unusual utility function). The point is emphasised in Browning et al. (2006). In practice, household bargaining weights may well be insensitive to relatively small changes in policy variables in which case the unitary model can be used.

Households differ from individuals in a number of ways, but household preferences, as revealed by household choices, need not correspond to some average of individual preferences. Groups behave differently to individuals, as Kerr et al. (1996) summarise in a survey of group decision-making. On the one hand, groups seem to make better decisions when there is a unique correct answer (Kocher and Sutter 2005). If that is true for households, then we might expect fewer errors in information processing when households are required to make choices, compared to the outcome of individual choice. On the other hand, often the preferences revealed by the group are not a weighted average of the preferences of the 
individual members of the group. They may be more or less extreme. In Bateman and Munro (2005) for instance, married couples were more risk averse when making choices jointly compared to situations where they made separate choices. Meanwhile, as reported in this issue (Bateman and Munro 2009), when we undertake a follow-up study using a choice experiment we find that willingness to pay (WTP) for improvements in food qualities are more extreme in couples' joint decisions than in individual responses. Similarly, in this issue Beharry et al. (2009) report research where both partners are interviewed separately and then jointly. They seek to understand how the joint WTP figures for beach resort quality are related to the individual perspectives. They too find that couples' responses are often more extreme than those for partners. Interestingly they also find that the influence of individuals varies across attributes. Such a result is at variance with collective models (where there is only one bargaining weight per person that applies to utility rather than individual goods or attributes). It suggests either that preferences are shaped through the process of joint decision-making or that there is an exchange of information (perhaps about preferences) that modifies individual viewpoints.

These studies represent preliminary work that hints at the complexities of household decision-making. They are also stated preference exercises. In fact most of the work on the household and environmental valuation has taken place within stated preference frameworks. Incorporating a richer model of the household into revealed preference approaches represents a research challenge, but would provide a payoff in the form of a better understanding of the structure of behavioural responses to policy changes. Some initial steps are provided by the work of Zhang et al. (2005) on household time allocation and transport use in the Netherlands. Though their model is essentially a unitary one, it introduces multiple time budgets for family members and estimates a comprehensive model of time allocation.

\subsection{How Best to Measure the Welfare of Households}

Notwithstanding the important work of Quiggin (1998), Strand (2007), the enlightening piece by Bergstrom (2003) and others, we still do not have a clearly useful theory of the relationship between measures of individual welfare and measures that emerge from household decisions. I stress the word useful because it seems obvious that there are a variety of households, not just one type. Thus, a good theory either has to apply to different types of households or it should provide a diagnostic test so that the researcher can identify the type of household. The results in Bateman and Munro (2009) suggest that none of the simple theories that link individual and household measures of surplus work particularly well. Household WTP is not equal to individual WTP; it is not an average of individual WTP; it is not the minimum of WTP (as proposed in Bergstrom 2003) and it is not the sum of individual WTP. Lindhjem and Navrud (2009) also in this issue, illustrate a second problem with trying to measure surplus when individuals are part of households. In their contingent valuation exercise for forest protection in Norway, respondents are asked to give WTP figures from two different perspectives: as an individual and on behalf of the household. Understandably, different WTP figures for the household are often produced by the subjects, although many of them do give the same answer to both questions. Unfortunately, in most standard valuation exercises, interviewers are vague about whether respondents should think as individuals or seek to value on behalf of their entire household.

One general question that arises with all the stated preference studies is whether the household really is the appropriate decision unit. Introspection and casual observations suggests that in many families a good portion of household decisions are made in a decentralised 
fashion-i.e. without a detailed discussion between partners. Unlike buying a new home or moving job, the weekday lunchtime bowl of noodles or the purchase of a magazine are rarely the result of some agreed plan or bargain. If some environmentally relevant decisions are also made in a similar fashion, then the valuation researcher needs to understand where in the household relevant values are generated.

Perhaps most fundamentally we do not have agreed measures of household welfare, the collective equivalents of compensating and equivalent surplus. To a degree the issue is philosophical: do we respect the assignment of resources within the household or not? In societies where households form voluntarily, where exit is possible and not punitive we might generally respect the internal decision-making of couples whatever form it takes. In other words the principle of consumer sovereignty that provides one part of the justification of individual surplus measures, would also extend to institutions into which individuals have voluntarily entered. For such societies, if one individual in a couple is made worse off by proposal $\mathrm{x}$ and one person is better off, but jointly the household is willing to accept the proposal then so be it. If we take this approach, then revealed preference measures can be used as a yardstick to evaluate potential stated preference measures of household welfare. ${ }^{1}$

It is important not to confuse the issue with the debate within cost-benefit analysis over double counting when some individuals are altruistic. That applies when each individual is autonomous and controls his or her own income. Within households either the budget is jointly controlled or one person controls resource allocation on behalf of all members. Let $W$ = social welfare and using $U, V$ for the utilities of the members of the household again and use $\lambda$ as the weight placed internally on the utility of the second partner. The question here is whether to use $W(U+\lambda V)$ or $W(U, V)$ as the basis for welfare evaluation in a situation where only information on $U+\lambda V$ is readily available.

In societies where there is less individual freedom in the creation of households or where exit is costly when it is feasible, the principle of household sovereignty appears less than compelling. If, in a unitary household of two people, one person controls all the resources and uses them to maximize $U+\lambda V$, and in addition $\lambda=0$, then household WTP is completely unaffected by the preferences of the partner. That is inequitable, but if, for instance, $\lambda$ is positive, but equals 0.0000001 , household WTP still does not look like a good reflection of individual welfare changes. ${ }^{2}$

A similar dilemma also applies to children, in the sense that household exit for young children is also not possible. As a consequence, there is no automatically compelling reason why the internal welfare weights attached by families to children should be respected in costbenefit analysis (see Hoffmann 2007 or Pearce et al. 2006 for discussion of these issues). Having said that, it is probably parents who know best their children's preferences which suggests that they should be the source of information on marginal rates of substitution between goods consumed by the child (Munro 2009). As Harbaugh (2001), though points out, experimental evidence suggests that older children are as rational as adults in their choices.

\subsection{How to Identify Individual Preferences Towards the Environment}

As we noted above, environmental risks and their perception vary systematically across individuals. What about preferences? There is some limited empirical work on differences in environmental preferences (e.g. Dupont 2004; Teal and Loomis 2000), but when individuals

\footnotetext{
1 This is an important empirical exercise that has yet to be undertaken.

2 In fact many gender empowerment exercises (e.g. as considered in Agarwal 2001) can be seen as attempts to change $\lambda$.
} 
are part of a household, recovering information on individual preferences becomes problematic. In the unitary household for instance, only the household preferences are revealed, not those of the individual members. Thus any differences between genders for instance are masked by membership of households. As we have just noted, basing policy on respect for household decisions may be ethically unacceptable. In other cases, having only data on household behaviour can be misleading when new policies affect individuals in a household differentially. The example of the carbon tax provided above gives an instance. In fact, there is relatively little work on the identification of individual environmental preferences from revealed household choices. Smith and Van Houtven (2004) is a notable exception which applies the methods developed by Chiappori and colleagues (e.g. Browning and Chiappori 1998) to the problems of estimating consumer surplus. Browning and Chiappori show that in general, in a collective household, individual preferences can be recovered if either the income sharing rule is known or there are purely private goods (i.e. goods that are exclusively consumed by one person) for each person. Identification for non-cooperative models of the household is more complex (see Lechene and Preston 2007), but follows similar lines. This formal approach to identification is becoming widespread within labour and household branches of the discipline, but is yet to catch on in environmental economics. Yet, there is certainly scope for more formal work on how to identify individual preferences towards the environment from revealed preference data, both theoretical and applied. In the case of theory, particular areas needing further clarification include the conditions under which preferences towards public goods can be recovered from household level data and secondly, the development of models that incorporate time use (e.g. for transport) as well as the consumption of commodities.

\subsection{What Difference Do Children Make?}

In nearly every theoretical model and nearly every applied model of the household, children are passive objects. Parents may bargain, children may react to actions taken by the adults, but they do not play a part in the actual decisions of the household. As people with children will already understand, the reality is different.

Consider for example, a two person household with a parent and a child who bargain over the child's behaviour, $b$ and about how much effort to be put into recycling waste, $g$. Let $M$ be the parent's resource endowment, $g$ the amount of time spent on recycling with $p$ as its opportunity cost and let $b$ be the effort the child puts into being "good" (doing their homework, smiling rather than scowling, helping with chores etc.) which has some upper limit of $B$. Parents enjoy life if their children behave but do not get any satisfaction directly from recycling. Meanwhile, the child would prefer recycling to occur, but finds being "good" costly, so that we have the following utility functions for parent and child respectively.

$$
\begin{gathered}
U=(M-p g) b \\
V=g(B-b)
\end{gathered}
$$

If we simply predict $g$ on the basis of the parent's preferences then we get an answer of zero- - the parent does not actually enjoy recycling. But if there is bargaining between parent and child, then perspectives change. With bargaining within the family the fallback position is unlikely to be dissolution of the household. Instead, following Lundberg and Pollak we might suppose it would be the non-cooperative equilibrium of the game where parent chooses $\mathrm{g}$ and child chooses $b$. In this equilibrium, $b=0$ and the parent sets $g=0$. Thus conveniently for the analysis, fallback utility $U=0=V$. Now suppose that in bargaining the child has a 
strictly positive weight $\alpha<1$. The generalised Nash bargaining solution can then be found by choosing $\mathrm{g}$ and $\mathrm{b}$ to maximize, $(M-p g) b(g(B-b))^{\alpha}$. At the solution, $g=\alpha M /(p+\alpha)$ and $b=B / 1+\alpha$. Of course if the parent is altruistic, recycling will not be zero even in the absence of bargaining. A unitary model can easily describe a household that recycles because parents care about their children. However, consider the impact of a minimum recycling requirement, perhaps introduced by the local municipality. In the unitary model this has no impact on behaviour if the minimum is set low enough and thereby non-binding. In the bargaining model the minimum affects the fallback and therefore raises actual recycling behaviour.

As with other areas of the household and the environment there is still little work on the role of children in decision-making. Dosman and Adamowicz (2006) comment on the influence of children on choices for recreational decisions and there is a small segment of the consumer research literature that documents the impact that children have on household choices (e.g. Arora and Allenby 1999; Dellaert et al. 1998 or Vaughan et al. 2003 for an environmental application). More recently, Lundberg et al. (2007) have produced a non-cooperative model of the household in which children play an active part, while Dauphin et al. (2008) modify the Browning and Chiappori model and use the UK Expenditure and Food Survey to identify the significant influence of older children in non-durable purchases.

\section{Conclusions}

The contributors in this issue consider the heterogeneity of household behaviour from a variety of angles. They show individually and jointly why understanding the household matters for environmental economics. Most of the emphasis is on the measurement of preferences for valuation purposes, but as I have stressed there are many other gaps in our knowledge, particularly in analytical models of environmental policy that are based on non-unitary models. In the future, perhaps that will not be the case.

\section{References}

Agarwal B (2001) Participatory exclusions, community forestry and gender. World Dev 29(10):1623-1648. doi:10.1016/S0305-750X(01)00066-3

Alderman H, Chiappori P-A, Haddad L, Hoddinott J, Kanbur R (1995) Unitary vs. collective models of the household: is it time to shift the burden of proof? World Bank Res Obs 10(1):1-19. doi:10.1093/wbro/ 10.1.1

Anderson S, Baland J-M (2002) The economics of Roscas and intrahousehold resource allocation. Q J Econ 117(3):963-995. doi:10.1162/003355302760193931

Apps P, Rees R (2009) Public economics and the household. Cambridge University Press, Cambridge

Arora N, Allenby GM (1999) Measuring the influence of individual preference structures in group decisionmaking. J Mark 25:476-487

Attanasio O, Lechene V (2002) Tests of income pooling in household decisions. Rev Econ Dyn 5(4):720-748. doi:10.1006/redy.2002.0191

Barua D, Greenough WB (1992) Cholera. Springer, New York

Bateman IJ, Munro A (2005) An experiment on risky choice amongst households. Econ J 115(502):C176C189. doi:10.1111/j.0013-0133.2005.00986.x

Bateman IJ, Munro A (2009) Household versus individual valuation: what's the difference? Environ Resour Econ (this issue)

Beharry N, Hensher DA, Scarpa R (2009) An analytical framework for joint vs separate decisions by couples in choice experiments: the case of coastal water quality in Tobago. Environ Resour Econ (this issue)

Bergstrom T (2003) Benefit cost analysis and the entanglements of love. Mimeo U.C. Santa Barbara 
Browning M, Chiappori P-A (1998) Efficient intra-household allocations: a general characterization and empirical tests. Econometrica 66(6):1241-1278. doi:10.2307/2999616

Browning M, Chiappori P-A, Lechene V (2006) Collective and unitary models: a clarification. Rev Econ Househ 4:5-14. doi:10.1007/s11150-005-6694-2

Bruce N, Perez-Padilla R, Albalak R (2000) Indoor air pollution in developing countries: a major environmental and public health challenge. Bull World Health Organ 78(9):1078-1092

Dauphin A, El Lahga A-R, Fortin B, Lacroix G (2008) Are children decision-makers within the household? CIRPEE Cahier de recherche/Working Paper 08-29

Dellaert BGC, Prodigalidad M, Louviere JJ (1998) Family members' projections of each other's preference and influence: a two-stage conjoint approach. Mark Lett 9(2):135-146. doi:10.1023/A:1007904931283

Dickie M, Gerking S (2009) Family behaviour: implications for health benefits transfer from adults to children. Environ Resour Econ (this issue)

Dosman D, Adamowicz W (2006) Combining stated and revealed preference data to construct an empirical examination of intra-household bargaining. Rev Econ Househ 4:15-34. doi:10.1007/s11150-005-6695-1

Dupont DP (2004) Do children matter? An examination of gender differences in environmental valuation. Ecol Econ 49(3):273-286. doi:10.1016/j.ecolecon.2004.01.013

EPA (2003) Children's health valuation handbook. US Environmental Protection Agency, Washington, DC

Flynn J, Slovic P, Mertz CK (1994) Race, gender and perception of environmental health risks. Risk Anal 14(6):1101-1108. doi:10.1111/j.1539-6924.1994.tb00082.x

Frondel M, Vance C (2009) Do high oil prices matter? Evidence on the mobility behaviour of German households. Environ Resour Econ (this issue)

Hammitt J, Stackelberg K (2009) Use of contingent valuation to elicit willingness-to-pay for the benefits of developmental health risk reductions. Environ Resour Econ (this issue)

Harbaugh WT, Krause K, Berry TR (2001) GARP for kids: on the development of rational choice behaviour. Am Econ Rev 91(5):1539-1545

Hoffmann S (2007) Since children are not little adults-socially-what's an environmental economist to do? Duke Environ Law Policy Forum 17(2):209-232

Huhtala A, Pouta E (2009) Benefit incidence of public recreation areas-have the winners taken almost all? Environ Resour Econ (this issue)

Kerr NL, MacCoun RJ, Kramer GP (1996) Bias in judgment: comparing individuals and groups. Psychol Rev 103(4):687-719. doi:10.1037/0033-295X.103.4.687

Kocher MG, Sutter M (2005) The decision maker matters: individual versus group behaviour in experimental beauty-contest games. Econ J 115(500):200-223. doi:10.1111/j.1468-0297.2004.00966.x

Landrigan PJ, Garg A (2002) Chronic effects of toxic environmental exposures on children's health. Clin Toxicol 449:453-454

Lechene V, Preston I (2007) Demand properties in household Nash equilibrium. Inst For Fiscal Stud WP07(01)

Lindhjem H, Navrud S (2009) Asking for individual or household willingness to pay for environmental goods? Implication for aggregate welfare measures. Environ Resour Econ (this issue)

Lundberg SJ, Pollak RA, Wales TJ (1997) Do husbands and wives pool their resources? Evidence from the United Kingdom child benefit. J Hum Resour 32(3):463-480. doi:10.2307/146179

Lundberg SJ, Romich K, Tsang P (2007) Decision-making by children. Discussion Paper No. 2952 July IZA

Munro A (2009) Public policy and bounded rationality: a perspective from behavioural economics. Springer, New York

Oosterlee A, Drijver M, Lebret E, Brunekreef B (1996) Chronic respiratory symptoms in children and adults living along streets with high traffic density. Occup Environ Med 53(4):241-247. doi:10.1136/oem.53. 4.241

Pearce DW, Atkinson G, Mourato S (2006) Cost-benefit analysis and the environment: recent developments. OECD Publishing, Paris

Quiggin J (1998) Individual and household willingness to pay for public goods. Am J Agric Econ 80:58-63. doi: $10.2307 / 3180268$

Smith VK, Van Houtven G (2004) Recovering Hicksian consumer surplus within a collective model: Hausman's method for the household. Environ Resour Econ 28(2):153-167. doi:10.1023/B:EARE. 0000029916.05630 .89

Stern RS, Weinstein MC, Baker SG (1986) Risk reduction for non-melanoma skin cancer with childhood sunscreen use. Arch Dermatol 122:537-545. doi:10.1001/archderm.122.5.537

Stern P, Dietz T, Kalof L (1993) Value orientations, gender, and environmental concern. Environ Behav 25(3):322-348. doi:10.1177/0013916593255002

Strand J (2007) Public-good valuation and intra-family allocation. Environ Resour Econ 38:527-543

Teal GA, Loomis JB (2000) Effects of gender and parental status on the economic valuation of increasing wetlands, reducing wildlife contamination and increasing salmon populations. Soc Nat Resour 13(1):1-14. doi:10.1080/089419200279207 
Vaughan C, Gack J, Solorazano H, Ray R (2003) The effect of environmental education on school children, their parents, and community members: a study of intergenerational and intercommunity learning. J Environ Educ 34:12-21

Vineis P, Forastiere F, Hoek G, Lipsett M (2004) Outdoor air pollution and lung cancer: recent epidemiologic evidence. Int J Cancer 111:647-652. doi:10.1002/ijc.20292

Wagner W, Blais L (2007) Children's health and environmental exposure risks: information gaps, scientific uncertainty, and regulatory reform. Duke Environ Law Policy Forum 17(2):249-282

Zhang J, Timmermans HJP, Borgers A (2005) A model of household task allocation and time use. Transp Res Part B 39(1):81-95. doi:10.1016/j.trb.2004.03.001

Zwarteveen M, Meinzen-Dick R (2001) Gender and property rights in the commons: examples of water rights in South Asia. Agric Hum Values 18:11-25. doi:10.1023/A:1007677317899 